\title{
Efficient tartaric stabilisation of white wine with potassium polyaspartate
}

\author{
R. Eder ${ }^{\mathrm{a}}$, M. Willach, M. Strauss, and C. Philipp \\ Höhere Bundeslehranstalt und Bundesamt für Wein-und Obstbau, Wiener Strasse 74, 3400 Klosterneuburg, Österreich, Austria
}

\begin{abstract}
The aim of this work was to test the tartaric stabilising effect of potassium polyaspartate (KPA) in comparison to metatartaric acid and carboxymethylcellulose (CMC). Wines of the varieties Chardonnay and Rheinriesling (vintage 2017) were used, furthermore their instability was increased by addition of potassium and tartaric acid. The samples were stored at $2{ }^{\circ} \mathrm{C}$ and $20^{\circ} \mathrm{C}$ and analyzed after 70,120 and 175 days. Results showed that the non-stabilized wines exhibited significant precipitations of potassiumhydrogentartrate at both temperatures. The stabilizer CMC could not prevent precipitation in the base wines at $20^{\circ} \mathrm{C}$. For the enriched wines the stabilising effect of $\mathrm{CMC}$ was inadequate. Although metatartaric acid gave sufficient stabilization in most variants, in enriched Rheinriesling the stabilising effect lessened after prolonged storage at $2{ }^{\circ} \mathrm{C}$ and a tartaric precipitate was detected. Only the wines stabilized with potassium polyaspartate remained blank at all dates and variants and showed no loss of potassiumhydrogentartrate. Control of the residual levels of tartaric acid and potassium after storage confirmed these results. Therefore it can be stated that of the three stabilizers tested, only potassium polyaspartate, even at half the recommended application rate, prevented the precipitation of Weinstein in all variants and thus had the best tartaric stabilising effect.
\end{abstract}

\section{Introduction}

If consumers want to enjoy a wine, it should be free of tartaric crystals (MARBE-SANS, 2016). First and foremost, a clear product is expected for the wine product. This could simply make it difficult to market the product of wine in the case of visible precipitations in the bottle. In some countries, such as Russia, wine is not marketable with tartaric acid precipitate. In the US, Weinstein precipitate is considered a sign of bad cellar practice (EDER, 2003). Tartaric stabilization is therefore an essential part of winemaking. Basically tartaric stabilisation can be distinguished in subtractive and additive processes. In the subtractive processes, the tartaric acid precipitation is induced in the cellar. This is done either by cold and addition of contact potassiumhydrogentartrate or the precipitate forming components (tartaric acid and/or potassium) are removed by physical processes such as electrodialysis.

In additive processes, stabilization takes place by the addition of crystallization inhibitors, the so-called inhibitors. This can be done by the addition of metatartaric acid, carboxymethylcellulose (CMC), mannoproteins or gum arabic. With the approval of potassium polyaspartate, there is another option for tartaric stabilization. Now the question arises as to how this product compares with the already established agents metatartaric acid and CMC.

Potassium polyaspartate, with the molecular formula $\left[\mathrm{C}_{4} \mathrm{H}_{5} \mathrm{NO}_{3} \mathrm{~K}\right]_{\mathrm{n}}$ is an odorless, light brown powder with usually $90 \%$ dry matter. It is completely soluble in water, with the potassium polyaspartate content of the anhydrous

\footnotetext{
a e-mail: Reinhard.Eder@weinobst . at,

www . weinobstklosterneuburg. at
}

substance being at least $98 \%$. For the preparation of potassium polyaspartate, the monomeric L-aspartic acid is used, which is formed by fermentation. Upon heating, monomeric L-aspartic acid is converted to insoluble polysuccinimide. Subsequently, the polysuccinimide is treated under controlled conditions with potassium hydroxide to obtain KPA.

Potassium polyaspartate acts as a protective colloid and thus inhibits tartaric acid precipitation (O.I.V., 2017). The pure potassium polyaspartate is powdery and is dissolved with deionized water and conserved using $\mathrm{SO}_{2}$. The $\mathrm{SO}_{2}$ concentration in the finished product is $0.3 \%$ (TRIULZI, 2017, BOIANCHINI, 2017).

Regulation (EU) 2017/1961 authorized the treatment of wine with potassium polyaspartate. The maximum quantity may not exceed $10 \mathrm{~g} / \mathrm{hl}$. At higher doses, the stabilising effect would not be improved, and in some cases even clouding might occur (O.I.V., 2016). There is no information on the stabilization of calcium tartrate. So far no negative effects on the filtration performance are known. Potassium polyaspartate is offered as a liquid product and does not need to be dissolved like other preparations. However, the wines must be protein-stable (SCHEDLER, 2018).

\section{Material and methods}

\section{Experimental design}

With the aim of achieving a broad impact on the effects of KPA, wines from two varieties (Chardonnay and Rheinriesling, vintage 2017) were selected, which have different tartaric and potassium contents. In order to further examine its effectiveness, part of the base wines

(C) The Authors, published by EDP Sciences. This is an Open Access article distributed under the terms of the Creative Commons Attribution License 4.0 (http://creativecommons.org/licenses/by/4.0/). 
Table 1. Composition of experimental wines.

\begin{tabular}{|l|c|c|}
\hline & Chardonnay & Rheinriesling \\
\hline Relative density & 0.9911 & 0.9906 \\
\hline $\begin{array}{l}\text { Effective alcohol } \\
(\% \text { vol })\end{array}$ & 13.0 & 13.2 \\
\hline Sugar content $(\mathrm{g} / \mathrm{l})$ & $<1.7$ & $<1.7$ \\
\hline Fructose $(\mathrm{g} / \mathrm{l})$ & 1.5 & $<1.1$ \\
\hline Glucose $(\mathrm{g} / \mathrm{l})$ & n.n. & n.d. \\
\hline $\begin{array}{l}\text { Titratable acidity } \\
\text { (g/l tartaric acid) }\end{array}$ & 5.6 & 6.3 \\
\hline pH-value & 3.32 & 3.16 \\
\hline Volatile acidity $(\mathrm{g} / \mathrm{l})$ & 0.3 & 0.6 \\
\hline Tartaric acid $(\mathrm{g} / \mathrm{l})$ & 2.4 & 3.6 \\
\hline L- malic acid $(\mathrm{g} / \mathrm{l})$ & 2.0 & n.d. \\
\hline Lactic acid $(\mathrm{g} / \mathrm{l})$ & n.d. & 0.9 \\
\hline Potassium $(\mathrm{mg} / \mathrm{l})$ & 702 & 506 \\
\hline
\end{tabular}

Table 2. Tartaric stabilising agents used.

\begin{tabular}{|l|c|c|c|}
\hline $\begin{array}{l}\text { Stabilising } \\
\text { agent }\end{array}$ & $\begin{array}{c}\text { Trade } \\
\text { name }\end{array}$ & Trader & $\begin{array}{c}\text { Recommended } \\
\text { application } \\
\text { amount }\end{array}$ \\
\hline Metatartaric acid & Metavin $^{\circledast}$ Opti & Erbslöh & $10 \mathrm{~g} / \mathrm{hl}$ \\
\hline CMC & VinoStab $^{\circledast}$ & Erbslöh & $130 \mathrm{ml} / \mathrm{hl}$ \\
\hline KPA & Zenith uno $^{\circledast}$ & Enartis & $100 \mathrm{ml} / \mathrm{hl}$ \\
\hline KPA & Zenith uno $^{\circledast}$ & Enartis & $50 \mathrm{ml} / \mathrm{hl}$ \\
\hline
\end{tabular}

were artificially rendered unstable in a further series of experiments by the addition of tartaric acid $(1.0 \mathrm{~g} / \mathrm{l})$ and potassium $(0.5 \mathrm{~g} / \mathrm{l})$.

Since this addition leads to a shift in the isoelectric point, the protein stability was checked again in these samples and found to be sufficient.

Since the formation of crystallization-promoting microcrystals can very rapidly occur due to the addition of tartaric acid and potassium, the stabilizers (Table 2) were added before the addition of tartaric acid and potassium.

The stabilizers metatartaric acid, CMC and KPA were added in each series of experiments at the maximum recommended rate. Since the aim of this study was to test the effectiveness of KPA, also variants with half the application rate of KPA were prepared. In each series of experiments there was a variant without the addition of a stabilizer, the reference sample. The wines of each test series were stored at two different temperatures $\left(2{ }^{\circ} \mathrm{C}, 20^{\circ} \mathrm{C}\right)$. In order to be able to carry out statistical calculations, three repetitions were applied per test variant. Three times 27 liters and twice 18 liters were needed per base wine.

The amount of the stabilising agents was weighed by means of an analytical balance in a beaker and dissolved in wine. Subsequently, the solution was filled in the balloons and stirred. The filling of each sample of all variants was carried out by means of a row filler in white $0.75 \mathrm{~L}$ wine bottles with screw caps. Thereafter, the storage was carried out at $2{ }^{\circ} \mathrm{C}$ and $20^{\circ} \mathrm{C}$. After 70,120 and 175 days bottles were removed for analysis.

\section{Chemical-physical analyses}

The determination of the amount of potassiumhydrogentartrate precipitate was carried out optically and then gravimetrically. The samples were filtered through a soft filter. Subsequently, the filters (type $5951 \frac{1}{2}$, Whatman plc, United Kingdom) were dried and weighed the tartaric precipitate contained therein. The filter including the precipitated Weinstein was dried in a drying oven at $160^{\circ} \mathrm{C}$ for 25 minutes, then transferred to a small beaker, weighed by analytical balance and converted to 1 liter.

The determination of the tartaric saturation according to the mini-contact method was carried out by means of a check rod device (Fa. Göttert, Seeheim, -Jugenheim, Germany). The sample to be examined was cooled down to $0{ }^{\circ} \mathrm{C}$ and $1 \mathrm{~g} / 100 \mathrm{~mL}$ contact potassiumhydrogentarttat was added automatically. Due to the strong supersaturation of the sample solution, an immediate crystallization took place, which leads to the reduction of potassium and tartaric acid. The resulting decrease in conductivity is proportional to the tartaric instability and can be evaluated using stored conductivity curves. Values above $60 \mu \mathrm{S}$ are considered to be labile (BECKER et al., 2009).

At the last analysis time (after 175 days of storage) the potassium content was determined in the filtrate by means of an atomic absorption spectrophotometer (Barna and Grill, 1984).

The analysis of the tartaric acid concentration was carried out by means of FTIR (type WineScan, Foss, Hamburg, Germany). The statistical analysis was done by exploratory data analysis using SPSS 22000.

\section{Results and discussion}

\section{Optical control of tartaric precipitate in the bottles}

The results of the optical controls of a tartaric precipitate were comparable for the two varietes. In both varieties after 70 and 120 days at $20^{\circ} \mathrm{C}$ storage temperature only in the blank samples with potassium and tartaric acid a Weinsteinausfall was detectable. Also recognizable tartrate precipitate was found at $2{ }^{\circ} \mathrm{C}$ storage temperature in the blank sample (with and without the addition of potassium and tartar) and in the wine with addition and CMC as stabilizer. However in the enriched samples with added tartaric acid and potassium especially in the variant stored at $2{ }^{\circ} \mathrm{C}$ visible, crystalline precipitations were found in the non treated wines but also in the wines stabilized with $\mathrm{CMC}$ and metatartaric acid in both varieties.

\section{Gravimetrical analysis of precipitated potassium hydrogen tartrate ("Weinstein")}

In the case of Chardonnay's unaltered wines, at both storage temperatures $\left(2^{\circ}\right.$ and $\left.20^{\circ} \mathrm{C}\right)$ at none of the three measuring points, a tartaric precipitate could be weighed. More meaningful were the results in the wines with the addition of tartaric acid and potassium. At the storage temperature of $20^{\circ} \mathrm{C}$, a high amount of precipitate was measured in the unstabilized sample at all times, whereas all added stabilizers provided stable wines at all times. For the enriched wines with the addition of tartaric acid and potassium at a storage temperature of $2{ }^{\circ} \mathrm{C}$, the untreated sample already exhibited a tartaric precipitate at 


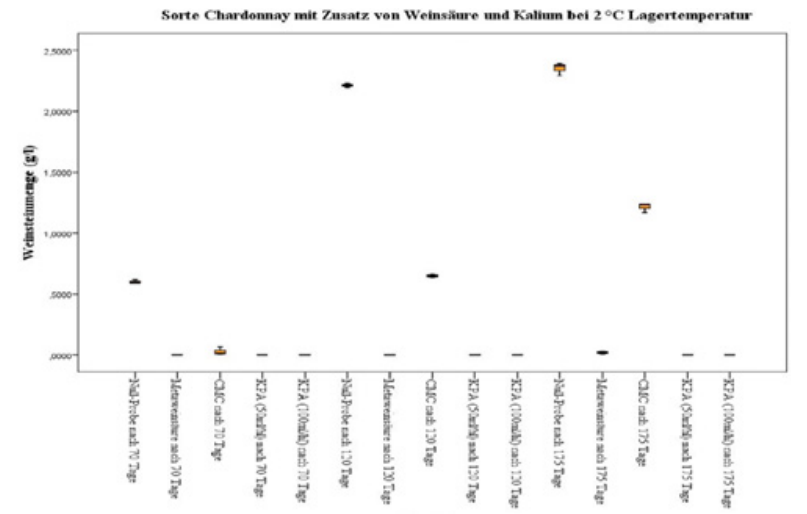

Figure 1. Amount of potassiumhydrogentartrate precipitate in wines of Chardonnay enriched with tartaric acid and potassium after 175 days storage at $2{ }^{\circ} \mathrm{C}$.

the first measurement point, which increased markedly at the second and third measurement times (2.2 and $2.5 \mathrm{~g} / \mathrm{l}$, respectively). Even the wine which was stabilized with CMC had a slight precipitate after 70 days, which also increased with storage time $(0.6$ or $1.2 \mathrm{~g} / \mathrm{l})$.

The metatartaric acid-stabilized variant was stable for the first two dates, but after 175 days a small cristallisation $(0.050 \mathrm{~g} / \mathrm{l})$ was observed. Only the variants stabilized with KPA showed no tartaric precipitation over the entire observation period, whereby it should be emphasized that the variant with half the recommended amount also provided sufficient stabilization.

With the unchanged wines of the variety Rheinriesling at a storage temperature of $20^{\circ} \mathrm{C}$ in no variant a precipitation of potassiumhydrogentartrate was measurable. In the variants stored at $2{ }^{\circ} \mathrm{C}$, however, in the comparative variants without stabilizer already after 70 days precipitated tartrate was weighed. In the variants stabilized with metatartaric acid, CMC and KPA, no tartrate precipitation was observed. For the enriched wines with the addition of tartaric acid and potassium at a storage temperature of $20^{\circ} \mathrm{C}$, a significant tartaric precipitation of $0.5-1.5 \mathrm{~g} / \mathrm{l}$ was observed for the non-stabilized control samples at all three times. Very meaningful results were obtained at $2{ }^{\circ} \mathrm{C}$ storage. In the comparison sample, a clear tartaric precipitation could be measured at all three measurement times (1.5-2.5 g/l). Even with CMCstabilized wines, a tartaric precipitate was already evident after 70 days, which increased to about $1.2 \mathrm{~g} / \mathrm{l}$ after 175 days of storage. Even with the variants stabilized with metatartaric acid a tartic precipitation was observed after 120 and 175 days $(0.050 \mathrm{~g} / \mathrm{l}$ and $1.500 \mathrm{~g} / \mathrm{l}$, respectively). While after 120 days storage, the amount of crystals in the metatartaric stabilized variant was significantly lower than in that one treated with $\mathrm{CMC}$, after 175 days of storage hardly a difference between the two wine treatment agents was recognizable. It was noteworthy that in both KPA-stabilized variants no tartaric precipitation could be detected. It can therefore be stated that the new stabilising agent KPA had the best effect of all inhibitors and had a sufficient effect even at half the recommended application rate.

It can also be stated that the results of the optical controls of a tartaric precipitate were in good agreement with the results of the gravimetric determination of the

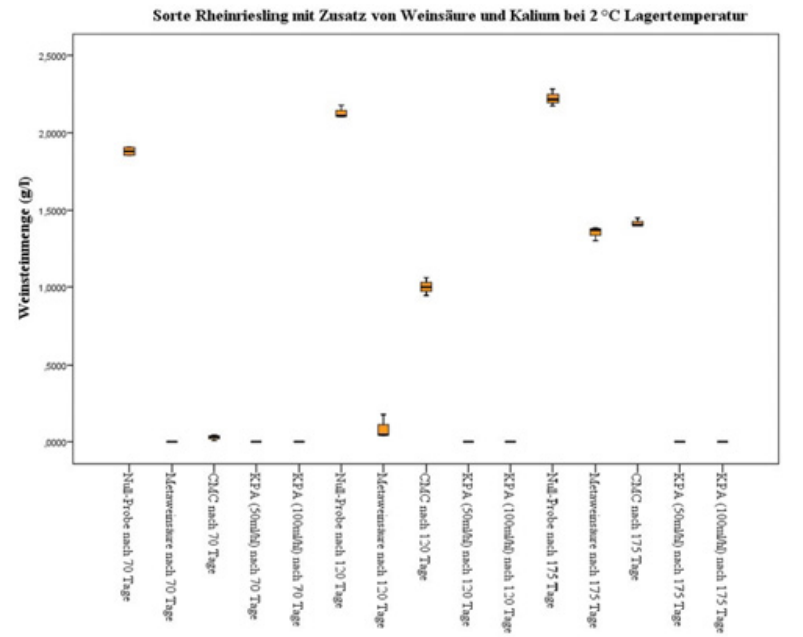

Figure 2. Amount of potassiumhydrogentartrate precipitate in wines of Rheinriesling enriched with tartaric acid and potassium after 175 days storage at $2{ }^{\circ} \mathrm{C}$.

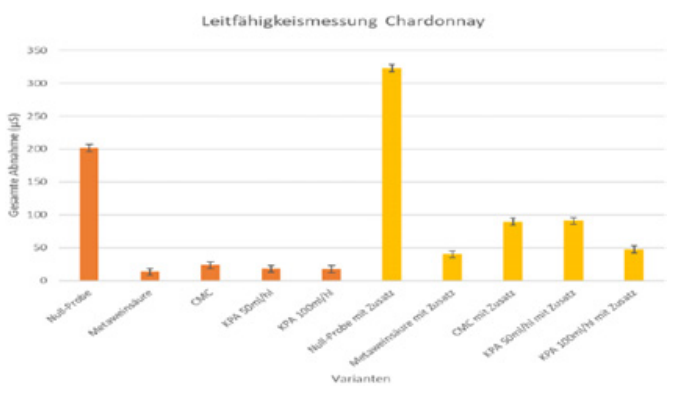

Figure 3. Tartaric instability measured by Minikontaktverfahren with Checkstab for Chardonnay variants.

potassiumhydrogentartrate precipitate. This means that all quantitative determined precipitates were not only of analytical interest but also for consumers visible.

\section{Determination of tartaric stability using Checkstab}

The analysis of the tartaric stability by means of Checkstab was carried out one week after addition of the stabilising agents in five repetitions per variant. In the case of the Chardonnay, a significant drop in conductivity of around $200 \mu \mathrm{S}$ was measured in the base wines without addition only in the non-stabilized comparison variant, which indicates instability. This results are in good accordance with the gravimetrically determined tartaric precipitate at a temperature of $2{ }^{\circ} \mathrm{C}$. As expected, the values of the conductivity decrease were higher for the wines with the addition of potassium and tartaric acid, in particular the non-stabilized variant had a very high value of around $320 \mu \mathrm{S}$. The variants stabilized with CMC and KPA $(50 \mathrm{ml} / \mathrm{hl})$ also showed values of about $90 \mu \mathrm{S}$, indicating instability $(>60 \mu \mathrm{S})$. However, this predicted tartaric precipitation did not happen in practical storage experiment in the variant KPA $(50 \mathrm{ml} / \mathrm{hl})$ even at a storage temperature of $2{ }^{\circ} \mathrm{C}$. On the other hand, in the variant stabilized with meta-tartaric acid, which according to the prognosis with Checkstab is relatively stable, it subsequently resulted in a tartaric precipitate at a storage temperature of $2^{\circ} \mathrm{C}$ after 175 days of storage. 


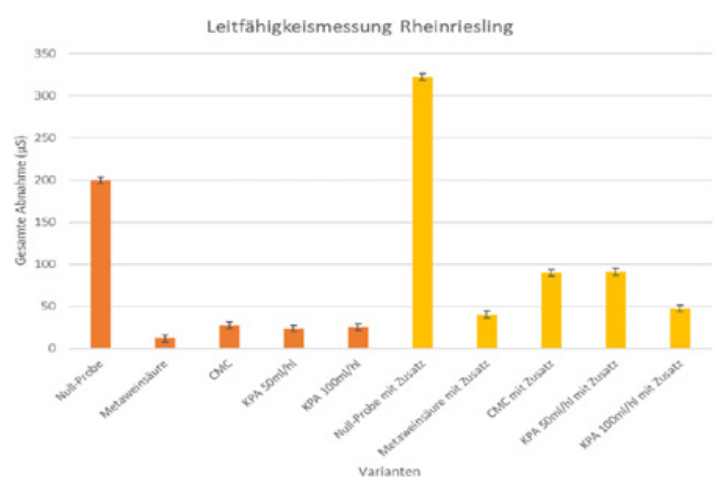

Figure 4. Tartaric instability measured by Minikontakt-verfahren with Checkstab for Rheinriesling variants.

The results of the Weinstein instability forecast using Checkstab for the variety Rheinriesling were comparable to that of Chardonnay. The analysis showed in the base wine variants without addition of potassium and tartaric acid again only in the non-stabilized variant a critical value of about $200 \mu \mathrm{S}$. This was confirmed by the results of storage at $2{ }^{\circ} \mathrm{C}$ after 175 days. Similar to the Chardonnay, the conductivity values for the variants CMC and KPA $(50 \mathrm{ml} / \mathrm{hl})$ were slightly above the critical value of $60 \mu \mathrm{S}$ in the variants with the addition of potassium and tartaric acid. However, these forecast values did not agree with the results of the practical storage experiments at $2{ }^{\circ} \mathrm{C}$, since in these cases the wines with metatartaric acid and CMC showed pronounced tartaric precipitation, whereas both variants stabilized with KPA had no crystal turbidity. Thus, it can be stated that the prognosis of the tartaric(in)stability with Checkstab, especially for wines with the addition of a stabilising agent, gives only limited reliable results.

\section{Residual contents of tartaric acid and potassium after 175 days of storage}

In addition to the measurements of potassiumhydrogentartrate precipitatye, the residual levels of tartaric acid and potassium were determined after 175 days of storage after filtering off the tartaric precipitate in the wines in order to have an additional control of results. For example, in the Chardonnay without the addition of tartaric acid and potassium at a storage temperature of $2{ }^{\circ} \mathrm{C}$ in the stabilized variants without tartaric precipitation a tartaric acid content of about $2.2 \mathrm{~g} / \mathrm{l}$ were detected, while this in the unstabilized reference sample due to the Weinstein precipitation the tartaric content decreased to $1.7 \mathrm{~g} / 1$. This is a significant difference (Kruskal Wallis test: $p=0.036$ ). With regard to the potassium content, the values in the nonstabilized variant were also significantly lower (around $500 \mathrm{mg} / \mathrm{l})$ than in the variants with stabilizer addition (around $650 \mathrm{mg} / \mathrm{l}$ ). A pairwise comparison with Kruskal Wallis test revealed statistically significant differences $(p=0.023)$ between the potassium levels.

The results were similar for the variety Rheinriesling. Thus, for example, the wines stabilized with KPA still had $3.4 \mathrm{~g} / \mathrm{l}$ tartaric acid after 175 days at a storage temperature of $2{ }^{\circ} \mathrm{C}$, while the non-stabilized variant only contained about $2.9 \mathrm{~g} / \mathrm{l}$ due to the tartaric precipitate. Similarly clear results were obtained for potassium, which was in the KPA-stabilized variants without tartaric precipitate around $520 \mathrm{mg} / \mathrm{l}$, while it decreased to around $350 \mathrm{mg} / \mathrm{l}$ in the nonstabilised variant with tartaric acid precipitaion. Also the differences of potassium content statistically significant (Kruskal Wallis test: $p=0.098$ ).

\section{References}

[1] M. Bogianchini, Technical Applications. Tagungsunterlagen Enartis (2017)

[2] J. Barna, F. Grill, Mitt. Klosterneuburg 30, 247 (1980)

[3] R. Eder, Weinfehler Linz: Agrarverlag (2003)

[4] D. Marbé-Sans, Dt. Weinmagazin 3, 12 (2016)

[5] O.I.V., Resolution OIV-OENO 543-2016, http:// www .oiv.int (2016)

[6] O.I.V., Resolution OIV-OENO 572-2017, http:// www . oiv .int (2017)

[7] S. Schedler, Forum Oenologie, Tagungsunterlagen, Bernkastel-Kues, Deutschland (2018)

[8] G. Triulzi, Tagungsunterlagen Enartis (2017) 